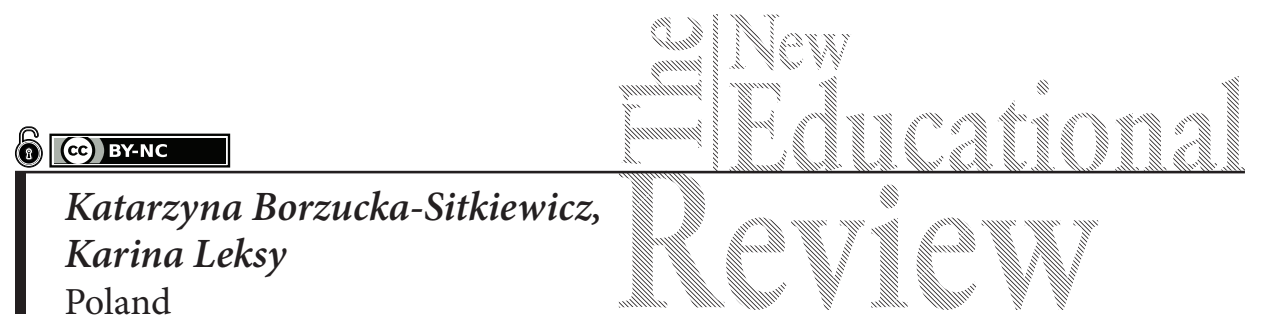

\title{
Cyberbullying as a New Problematic Behaviour Presented by Polish Youth
}

DOI: 10.15804/tner.2018.54.4.03

\begin{abstract}
The domination of new technologies in the lives of children and the youth leads to its consideration in the context of threats and a potential negative influence on adolescents' functioning. Considering various threats occurring in the virtual space, first of all it is indicated that the Internet, due to apparent anonymity, is often the space of mutual aggression, mocking and attempts to discredit other net users. The presented study refers to the analysis of behaviours being a demonstration of cyberbullying. The research was conducted in conformity with the quantity-quality paradigm. It involved a method of diagnostic survey using the technique of a questionnaire and documents analysis. As the conducted study showed, cyberbullying is a phenomenon which often occurs among contemporary teenagers. The examined persons were most often victims or witnesses of verbal aggression in the net.
\end{abstract}

Keywords: new technologies, Internet, cyberbullying, youth

\section{Introduction}

Undoubtedly, new media, especially the Internet, are an important environment of young people's lives and the virtual world often becomes for them "more real than the real one". It is even indicated that an adolescent creates for him/her a specific culture, the determinant of which is permanent and intensive use of mobile phones, computers and the Internet (Peker, Eroglu, Ada, 2012, pp. 185-206). The 
domination of new technologies in the lives of children and the youth leads to its consideration in the context of threats and a potential negative influence on the adolescents' functioning. Great freedom of the use of the Internet, the lack of clearly set borders and control of adults make a teenager to the largest extent exposed to negative behaviours in the net, such as aggression, stalking and threatening (Lazuras, Barkoukis, Ourda, Tsorbatzoudis, 2013, pp. 881-887). Considering various threats occurring in the virtual space, first of all it is indicated that the Internet due to apparent anonymity is often the space of mutual aggression, mocking and attempts at discrediting other net users. Such behaviours are described as cyberbullying and although this phenomenon has been known for approximately a decade, at present the scale of its occurrence is extremely high and on the world scale it ranges from $10 \%$ to $53 \%$ depending on the accepted definition of cyberbullying and the respondents' age group (Guo , 2016, p. 432).

Cyberbullying is defined as "a new dimension of bullying that includes deliberate and attitudes of an individual or a group that damage others through the use of information and communication technologies" (Langos, 2015, p. 106-123). The phenomenon is also defined as "the willful use of electronic technology (e.g., instant messaging, chat rooms, e-mail and text messages) as a means through which aggressive activities (e.g., threatening, harassing, disrespecting, or socially excluding another) are carried out deliberately and repeatedly toward a specific individual or group of individuals" (Hinduja, Patchin, 2007, pp. 89-112). Online bulling can be realized by using: emails, cell phones, pagers, instant messaging, short message services, internet chatrooms, blogs, forums, social network websites, websites and cameras (Beyazit, Şimşek, Ayhan, 2017, p. 1512). Moreover, this phenomenon is demonstrated in the following behaviours: insulting, victimisation, denigrating, spoofing, revealing secrets, exclusion, cyber-persecution, the so-called happy slapping, which is provoking or attacking a chosen person and recording this event with a mobile phone camera.

The consequences of cyberviolence often exceed the internet space. According to the Centers for Disease Control and Prevention (CDC), cyberbullying has become a problem of public health, against which preventive measures should be taken (Electronic Aggression: Technology and Youth Violence. Centers for Disease Control and Prevention, 2016). Research confirms that aggression in the internet causes negative physical and psychical consequences in all persons involved in it (Isenberger, 2016). At the same time, it is emphasized that the consequences for public health are the most serious ones (Miller, 2017, p. 385). Researchers indicate that victims of cyberbullying are characterized by such features as: low self-esteem, anxiety, loneliness, disappointment, sadness, fear, anger, psychotic symptoms, hos- 
tility and a high stress level. Such persons also demonstrate somatic symptoms and worse interpersonal relations (Donegan, 2012, pp. 33-42; Litwiller, Brausch, 2013, pp. 675-684). Also, the influence of cyberbullying on academic achievement and functioning in the school environment should be noted. Research indicates that the victims of persecution in the Internet have poorer achievements in learning, they lack motivation for learning at school, they miss classes more often and they perceive school as a place that does not provide a sense of security (Notar, Padgett, Roden, 2013, pp. 1-9). Moreover, the victims of net aggression are in a group of risk of: depression, self-injuries and other forms of self-damage, suicidal thoughts and attempts (Pappas, 2015; Com. Twenge, 2017). It is worth noting the most serious psychological consequence of cyberviolence, which is suicide. According to P. Hinduja and J.W. Patchin (2018), the victims of cyberattacks were almost twice more prone to suicidal attempts than those who did not experience violence in the net. What is more, the phenomenon of cyberviolence leads - indirectly or directly - to so many suicides that recently a concept of "cyberbullicide" has emerged (Hinduja, Patchin, 2010, pp. 206-216). Although cyberbullicide is not a standard among the cyberviolence victims, it is still such a serious problem that prophylactic and measures increasing social awareness in this scope should be taken (Miller, 2017, p. 388).

\section{Research Methodology}

The results described in this article constitute a part of a broader research project, the purpose of which was to determine characteristics of behaviours undertaken in the virtual space by pupils of Polish junior secondary schools as well as determination of potential social and health consequences of such behaviours. The presented excerpt of studies refers to the analysis of behaviours being a demonstration of cyberbullying.

The study was conducted in conformity with the quantity-quality paradigm. The quantity research was of diagnostic-verification nature, which means that the research questions had a form both of questions about variables and about relations between the variables. The study involved a method of diagnostic survey using the technique of a questionnaire and documents analysis. The author's survey questionnaire was used to conduct the research and it consisted of 41 questions, including 28 semi-open cafeteria questions, 4 closed cafeteria questions (rank order questions), 8 questions using the Likert scale (rating scale questions) and 1 open question (Thomas, 2013, pp. 207-217). Before proceeding to the stage of proper research, a pilot study was conducted. Thanks to the pilot study, necessary 
modifications of the research tool were made - some wordings were made more precise and small alterations were introduced in a few cafeterias. The obtained data were subjected to quantity and quality analysis. Program Statistica 12 was used to conduct statistical analysis. Within the frames of the quality paradigm, the technique of documents analysis was applied. Within the frames of the quality paradigm, the document analysis technique was applied. Within its frames, the contents of educational-prophylactic programmes in schools where the quantity research was conducted, in the context of issues concerning young people's behaviour in the Internet and potential threats related to them, including cyberbullying and its consequences, were analyzed.

The selection of persons for the studies was of non-probability nature (Thomas, 2013), and the selection criterion was the respondents' age. The research sample was a sample representative of the Silesia Province. 390 junior secondary school pupils from two schools located in urbanistically diversified areas were included. 164 persons were pupils of a small town school (under 10,000 inhabitants) and 226 persons attended a school in a big city (over 100,000 inhabitants). The respondents' age ranged from 13 to 16 and the largest group were 14-year-olds and 15-year-olds (82 and 74 pupils, respectively). Among the respondents there were 198 girls and 186 boys, and 6 respondents did not specify their sex.

Over $85 \%$ of the respondents used the Internet every day, doing it in various places, but most often at home and school. On days off, a vast majority of the respondents spent over 3 hours a day in the net, whereas on working days almost $40 \%$ of the respondents did so. Various devices were used to surf the net, not only computers or laptops, but first of all mobile phones as well as TVs, game consoles, iPads, etc.

\section{Research Results}

Due to the more and more spread phenomenon of cyberbullying among teenagers, this issue was one of the most important ones in the presented research. First of all it was verified if the respondents had encountered negative behaviours in the net at all. The obtained results showed that that as many as $56.7 \%$ of the participants often encountered such behaviours and 33.9\% of the junior secondary school pupils encountered them but they were individual cases. Summing up the above percentages, it was discovered that $90.6 \%$ of the teenage respondents were witnesses, victims or perpetrators of cyberviolence, which proves that this phenomenon is an urgent, current and very widespread problem. 
The next issue in the analyzed context was to check precisely what negative behaviours in the net were most often encountered by the examined youth. Similar results (over 70\%) were obtained in the case of three kinds of behaviours: using vulgar words (77.2\%), insulting other people (72.1\%), and making fun of them (70.3\%). An important issue were also negative, offensive comments under photos of Internet users, since this problem was mentioned by $53.0 \%$ of the respondents. It is also worth noting that as many as $35.6 \%$ of the pupils pointed out, among negative behaviours in the net, publishing discrediting photos of other people without their consent and knowledge, which undoubtedly demonstrates the seriousness and significant spread of such behaviours. The study also aimed at establishing whether there were statistically significant differences regarding the respondents' sex with reference to negative behaviours which they encounter in the Internet. Generally, it was found that the girls and boys equally often encountered negative behaviours in the net, but the type of such behaviours was different, which was verified with test $\chi^{2}$. Such behaviours as: insulting others, making fun of and negative and offensive comments under other people's photos.

While conducting the research, an attempt was also made to determine if the respondents had ever been cyberviolence perpetrators. Based on the obtained data, it can be stated that over three quarters $(76.3 \%)$ of the respondents claimed that they had never put other people in bad light. Only $14.2 \%$ admitted that they had written something negative about another person on the Internet (e.g., criticizing looks or behaviour). A small percentage of the examined pupils also admitted that they had made fun of other users of the net and written vulgar things about them (10\% and $9.8 \%$ respectively). Among other answers, such ones were found that confirmed that they had written negative things about other people on the net, such as "yes, unfortunately, I did it once", "I was writing but with consent of the other person and for fun", "once I placed an ugly photo of another person but I removed it". However, the majority of the answers in the category "other" prove that the respondents rather try to avoid such situations.

Based on the conducted analysis of the obtained results, it can be stated that $32.3 \%$ of the pupils have never been a victim of aggression in cyberspace and $26.9 \%$ do not recall such a situation. At the same time, summing up the answers confirming such negative experiences it turns out that the majority of the respondents have become a victim of some oppressive situation on the Internet (in total, $83 \%$ of indications to negative behaviours towards the respondents). In this context, the most commonly indicated behaviour was mocking (23.5\%) and vulgar words $(22.7 \%)$. Less often, in the case of $13.0 \%$ of the respondents, the person was negatively assessed based on a photo placed on the Internet and almost the same 
number of persons (12.9\%) admitted that their photo had been placed in the net without their consent. The respondents' answers in the "other" category also prove that there is a problem with the so-called hating. Among them there were: "they impersonated me"; "hates on ask"; "yes, somebody impersonated me"; "someone wrote to me that he/she saw my naked pictures on the Internet".

One subject of the analysis in the presented research were the feelings of the respondents facing situations hurting them in the net. However, the results obtained in this field show that $45.2 \%$ of the respondents did not worry about such situations at all. One may wonder whether the obtained result is a consequence of common occurrence of unpleasant situations in the net (e.g., negative comments, mocking, insulting other people, etc.) and treating them as a standard, or perhaps the relations and bonds on the Internet are so weak, impermanent and insignificant that young people do not care about unpleasant situations which take place in the virtual space. At the same time, $34.7 \%$ of the pupils declare that they feel sadness in such situations and $23.8 \%$ - anger. There were also many answers in the "other". category Among them, a lot of people wrote that they had never encountered such situations, whereas the persons who had had such experiences claimed: "I felt like demolishing inanimate objects"; "being superior to someone who offended me"; "compassion regarding the mental level of the person who insulted me"; "I laugh at stupidity of such people"; "it is for fun"; "laughter; "joy"; "indifference"; "it was not important to me".

The authors of the research tried to find out how young people dealt with unpleasant situations which they encountered in the net. In answer to the above issue, $39.0 \%$ of the junior secondary schools pupils declared that they did nothing whereas a little fewer persons (33.8\%) tried not to worry about such situations and not to think about them though it may be very hard. Almost a quarter of the respondents $(24.3 \%)$ try to find some activity to do (e.g., they relax, go for a walk, do sports), $21.0 \%$ of the respondents in similar situations confided in their friends, $15.8 \%$ presented the existing situation to their parents and only $4.1 \%$ of the pupils asked their tutors or teachers for help. In the case of this question, a number of different answers appeared. Many respondents declared that in such a situation they did not care about it at all ("I do not worry about it"; "It doesn't bother me"; "I don't give a damn"; "I do not care"; "I do not care about it so I do nothing in such a situation"; "I don't give a toss") or got involved in interactive games ("I play CS:GO"; "XBOX"; "I play computer games"; "I play CSA"). Some of them declared that they attempted to get back at the person who caused cyberviolence, e.g.: "I call a group of a few people and then either we meet this person in the real world or we press him/her on the Internet. No one pushes me around"; "I give a ban"; 
"they get a ban". Moreover, the respondents coped with unpleasant situations and emotions looking for other people's support (e.g., "I try writing with my friends about positive things"; "I ask my friend to comfort me"; "I say it to my sister") or taking up favourite activities (e.g., "I dance:; "I read, listen to music, fulfill my passions, write stories").

Within the frames of the research, also prophylactic-educational programmes of the school where the research was conducted were analyzed. In the school in Bytom, among the areas of prophylactic impacts there were issues, among others, connected with "Prophylactics of phonoholism and threats in the net". The basis for conducting psycho-educational classes was the diagnosis of the phenomenon made on the basis of a survey test. Next, a class was held on: cyberviolence, stalking, addiction to the Internet and computer games and sexting, using the film of Fundacja Dajemy Dzieciom Siłę (We Give Children Strength Foundation), titled "Forever". The implementers of the impacts were form teachers and a school pedagogue. Additionally, the pupils participated in a presentation on criminal liability of pupils, a psycho-educational class was organized for parents and an action procedure in the case of cyberviolence was prepared. In turn, in the school in Ożarowice, within the frames of Educational-Prophylactic Programme, a prophylactic class was held, which concerned, among other things: threats connected with new media overuse, safety in the net, dealing with the Internet "hate", legal aspects of using the Internet (regulations of using blogs, forums and other Internet tools) and consequences of negative behaviours in cyberspace. The school also participated in the "Safe in the Net" programme (sieciaki.pl). Moreover, the conducted educational-prophylactic classes aimed at strengthening pupils' self-esteem and emphasizing the significance of positive life experiences in offline reality, as well as teaching to express one's own emotions and dealing with stress in a constructive manner. The above contents were implemented within form periods and IT classes and their implementers were form teachers, IT teachers and a school pedagogue.

\section{Discussion and Conclusions}

As the conducted study showed, cyberbullying is a phenomenon which often occurs among contemporary teenagers. The examined persons were most often victims or witnesses of word aggression in the net. Unfortunately, taking into consideration the constantly growing availability of the Internet and new information-communication technologies, simultaneous spread of cyberbullying should be expected (Raskauskas, Stoltz, 2007, pp. 564-575). It is worth noting that the 
young people being in a situation of a cyberbullying victim tried to underestimate the existing situation or felt negative emotions (sadness, anger), but at the same time they did not take any preventive measures. Therefore, it seems that the teenagers treat the Internet aggression as a standard and their sensitivity to harming communication decreases, which leads to the situation when probably the analyzed phenomenon will spread.

Taking into account the respondents' lack of reaction to violence on the Internet, it is necessary to take actions aimed at, first of all, minimizing incidents and acts of hatred, to which any Internet user can be exposed. At the same time, due to the fact that the group most often involved in cyberbullying are teenagers, considering the critical moment of their development, the preventive measures should focus on them (Miller, 2017, pp. 385-386). Thus, first of all, it is important that young people should react to occurring incidents of cyberbullying (cf., https://www.stopbullying.gov/kids/what-you-can-do/index.html) and report them to adults - parents, tutors, teachers, the police. The role of adults in this context cannot be overestimated. Parental control is very important and lack of it makes teenagers more prone to cyberbullying (Fanti, Demetriou, Hawa, 2012, pp. 168-181; cf., Sengupta, Chaudhuri, 2011, pp. 284-290). At the same time, it is worth noting that the parents who cannot use information-communication technologies are usually unaware of both advantages and the risk connected with using the Internet by their children. It is also difficult for them to provide support when their child becomes a victim of cyberbullying (Monks, Mahdavi, Rix, 2016, pp. 39-48). Moreover, the research shows that the parents' lack of knowledge and awareness of potential threats to which their children can be exposed on the Internet makes them underestimate them (Kasikci, Cagiltay, Karakus, Kursun, Ogan, 2014, pp. 230-243). Therefore, it is necessary to teach parents in order to pass the knowledge and make them aware of the threats connected with the net. Thus, schools should not only undertake educational activities directed to parents but also implement prophylactic programmes concerning cyberbullying (its matter, symptoms), emphasizing the consequences of the phenomenon both for its victims and perpetrators. Teachers and tutors should pay special attention to aggressive pupils and those demonstrating behaviour disorders in the offline world, as the research confirms that such persons will more often present similar behaviours in the net. People who behave aggressively outside the Internet, demonstrating behaviour disorders and having a positive attitude to aggression and violence should be quickly identified in order to take actions aimed at their moral development and introduction to pro-social standards and values. At the same time, due to the multiple conditioning of the discussed phenomenon, in 
order to prevent it or decrease its spread, universal solutions and strategies based on multi-system therapy, parental skills training, peers support programmes and intervention forms based on positive school atmosphere and family background (Guo, 2016, pp. 441-444) should be used.

Finally, it is worth emphasizing that in the context of cyberbullying prophylactics, probably the most efficient prophylactic programmes will be those taking into account an individual, his/her personality features and perpetuated behaviour patterns, as well as the family environment, school atmosphere, peer pressure and a broader social context. Therefore, in the prevention of the phenomena, it is postulated to, first of all, use universal strategies and then take actions directed at a concrete individual and the features of the particular person which contribute to his/her becoming a victim or perpetrator of internet aggression (Guo, 2016, p. 444).

\section{References}

Beyazit U., Şimşek Ş., Ayhan A.B.: An examination of the predictive factors of cyberbullying in adolescents. „Social Behavior and Personality” 2017, 45(9).

Donegan R.: Bullying and cyberbullying: History, statistics, law, prevention and analysis. "The Elon Journal of Undergraduate Research in Communications" 2012, 3.

Electronic Aggression: Technology and Youth Violence. Centers for Disease Control and Prevention [http://www.cdc.gov./violenceprevention/youthviolence/electronicaggression/; accessed on 22.09.2016].

Fanti K.A., Demetriou A.G., Hawa V.V.: A longitudinal study of cyberbullying: Examining risk and protective factors. "European Journal of Developmental Psychology" 2012, 9.

Guo S.: A meta-analysis of the predictors of cyberbullying perpetration and victimization. "Psychology in the Schools" 2016, vol. 53 (4).

Hinduja S., Patchin J.: Offline consequences of online victimization. "Journal of School Violence" 2007, 6.

Hinduja S., Patchin J.W.: Bullying, Cyberbullying, and Suicide. "Archives of Suicide Research" 2010, 14 [https://www.researchgate.net/publication/45289246_Bullying_Cyberbullying_and_Suicide; 22.03.2016]

Hinduja S., Patchin J.W.: Cyberbullying Research Summary: Cyberbullying and Suicide. Cyberbullying Research Center [https://cyberbullying.org/cyberbullying_and_suicide; 22.03.2018]

https://www.stopbullying.gov/kids/what-you-can-do/index.html (accessed on 22.03.2018). Isenberger E.: Causes For Counseling: The Degree to Which Cyber Bullying Affects Mental Health. SocialPolicy.org [http://socialpolicy.org/spring-2013/534-causes-for-counseling-the-degree-to-which-cyber-bullying-affects-mental-health-; 14.10.2016]. 
Kasikci D.N., Cagiltay K., Karakus T., Kursun E., Ogan C.: The internet using habits and use of safe internet by children in Turkey and in Europe. "Education and Science" 2014, 39.

Langos C.: Cyberbullying: The shades of harm. "Psychiatry, Psychology and Law" 2015, 22 [accessed: https://doi.org/bshs].

Lazuras L., Barkoukis V, Ourda D., Tsorbatzoudis H.: A process model of cyberbullying in adolescence. "Computers in Human Behavior" 2013, 29 [accessed: https://doi.org/bsh4].

Litwiller B.J., Brausch A.M.: Cyber bullying and physical bullying in adolescent suicide: The role of violent behavior and substance use. "Journal of Youth and Adolescence" 2013, 42 [https://doi.org/bsh5].

Miller K.: Cyberbullying and its consequences: how cyberbullying is contorting the minds of victims and bullies alike, and the law's limited available redress. "Southern California Interdisciplinary Law Journal” 2017, vol. 26 Issue 2.

Monks C.P., Mahdavi J., Rix K.: The emergence of cyberbullying in childhood: Parent and teacher perspectives. "Psicologia Educativa” 2016, 22 [accessed: https://doi.org/bsh7].

Notar C.E., Padgett S.P., Roden J.R.: Cyberbullying: A review of the literature. „Universal Journal of Educational Research". 2013, 1.

Pappas S.: Cyberbullying on Social Media Linked to Teen Depression. LiveScience [http:// livescience.com/51294-cyberbullying-social-media-teen-depression.html; 22.06.2015].

19. Peker A., Eroglu Y., Ada S.: The investigation of predictors of cyberbullying and cybervictimization in adolescents (In Turkish). "Abant Izzet Baysal University Journal of Education" 2012, 12.

Raskauskas J., Stoltz A.D.: Involvement in traditional and electronic bullying among adolescents. "Developmental Psychology" 2007, 43.

Sengupta A., Chaudhuri A.: Are social networking sites a source of online harassment for teens? Evidence from survey data. "Children and Youth Services Review" 2011, 33 [dostęp: https://doi.org/b55km2].

Thomas G.: How to do your research project. London 2013.

Twenge J.M.: iGen. New York 2017. 